\title{
¿FUNCIONO UN SISTEMA SOCIOCULTURAL DISCRETO EN EL IBÁÑEZ MEDIO? EVALUANDO FRONTERAS MEDIANTE PROSPECCIONES EN LOS ANDES CENTROPATAGÓNICOS (AISÉN, CHILE)
}

CHRISTIAN GARCÍA P.a \& FRANCISCO MENA L. ${ }^{b}$

\begin{abstract}
RESUMEN
Localizado en la vertiente oriental de los Andes (Aisén, Chile) el valle del río Ibáñez presenta una gran diversidad ambiental en un espacio relativamente pequeño y confinado. No es sólo que se trate de un valle sin acceso al Pacífico y aislado por altas cumbres de las cuencas aledañas, sino que presenta características arqueológicas propias, distinguiéndose sobre todo por la abundancia de pinturas rupestres de un mismo tipo y por una ocupación relativamente acotada en el tiempo. Con el fin de poner a prueba la hipótesis de que en este valle existió en uno o varios momentos un sistema sociocultural relativamente cerrado, se prospectaron los alrededores de la zona donde se conoce la mayor cantidad de sitios. En este trabajo se dan a conocer los resultados de prospecciones sistemáticas y excavaciones de sondeo llevadas a cabo para evaluar los posibles límites del sistema cultural.
\end{abstract}

PALABRAS CLAVE: prospección, distribuciones arqueológicas, límites, Andes patagónicos.

\section{DID A DISTINCT SOCIOCULTURAL SYSTEM FUNCTION AT THE MIDDLE IBÁÑEZ RIVER? ASSESSING BOUNDARIES THROUGH SURVEYS AT THE CENTRAL PATAGONIAN ANDES (AISÉN, CHILE)}

\begin{abstract}
Located on the eastern slopes of the Central Patagonian Andes (Aisén, Chile), the Río Ibáñez valley encompasses a rich diversity of environments within short distances. This relatively bounded geographic space -separated from the Pacific and neighboring valleys by high mountain ranges- is further enhanced by a particular archeological record, most notoriously characterized by abundant rock paintings of great homogeneity within a bounded period of human occupations. With the aim of testing the likely existence of relatively closed, discrete cultural systems in prehistory, areas surrounding the main known concentration of archaeological sites were surveyed. Herein we report
\end{abstract}

\footnotetext{
Arqueólogo, investigador independiente. Las Magnolias 53, Parque Ivian, Puerto Varas. cuvieronius@gmail.com

b Centro de Investigación en Ecosistemas de la Patagonia (CONICYT-Regional R10C 1003). Simpson 471, Coyhaique.

francisco.mena@ciep.cl
} 
the results of systematic surveys and test excavations conducted to assess the possible boundaries of the cultural system.

KEY WORDS: survey, archaeological distributions, boundaries, patagonian Andes.

\section{INTRODUCCIÓN}

Aunque ha habido atisbos etnográficos de que no todos los indígenas de Patagonia continental hablaban una misma lengua ni constituían una sola unidad cultural (Escalada, 1949; Casamiquela, 1969; Falkner, 2013), esta idea no ha sido explorada en la arqueología patagónica dado que en grupos cazadores-recolectores la evidencia material suele referirse a la esfera de la tecnología subsistencial y es difícil aproximarse a dimensiones como la de "identidad étnica" o "microidentidad" (Bordieu, 1988; Giddens, 1994) en ausencia de marcadores territoriales $\mathrm{u}$ otros objetos (cerámica, vestimentas o pintura corporal perecibles) portadores de una fuerte carga estilística, que aun en estos casos suelen no asociarse a filiaciones lingüísticas ni identitarias (Richerson \& Boyd, 2006, p. 92).

Sin embargo, en el último tiempo algunos trabajos se han aproximado desde distintos puntos de vista a la posibilidad de diferenciar poblaciones o segmentos de las mismas a través de la investigación de formas particulares de hacer instrumentos, el arte rupestre, los rasgos funerarios, la variabilidad de los sistemas de movilidad y circulación, así como de la ecología isotópica (Borrero et al. 2008, 2009; Charlin \& Borrero, 2012; Franco, 2008, 2013). En este trabajo informamos acerca de los resultados obtenidos en prospecciones y sondeos desarrollados en el marco del proyecto FONDECYT 1110556, orientado a discutir la hipótesis de si en el curso medio del Río Ibáñez (Aisén, Chile) existió un sistema cultural territorialmente restringido (Mena, 2013).

Antes de interpretar el registro en términos de "microidentidad", sin embargo, debemos evaluar si existe una clausura, lo que resulta particularmente difícil en un espacio como éste, donde no podemos apoyarnos en otro argumento que no sea el registro arqueológico (dada la ausencia de crónicas o documentos etnohistóricos, así como de poblaciones indígenas). Hemos procurado definir en trabajos anteriores (Mena \& Lucero, 2004; Mena, 2013), si hay realmente peculiaridades locales en el arte rupestre u otros contextos artefactuales (que bien podrian deberse a diferencias funcionales $\mathrm{y} / \mathrm{o}$ estacionales), si el abastecimiento y circulación de materias primas líticas implica o no grandes desplazamientos o si hay una concentración de evidencias arqueológicas rodeadas de un vacío o, al menos, de una mucho menor densidad artefactual. Para evaluar este último tema, se llevaron a cabo prospecciones pedestres sistemáticas y excavaciones de sondeo en lo que consideramos a priori, podrían ser los límites de la distribución arqueológica conocida, en el valle del curso medio del río Ibáñez.

Considerando que la presencia humana en el valle del Ibáñez abarca varios miles de años, los conjuntos de superficie presentan problemas de resolución temporal para discutir la existencia de un sistema cultural territorialmente restringido. Algo similar sucede con el arte rupestre, del cual hasta ahora no contamos con dataciones. Sin embargo, los registros arqueológicos de superficie tienen una mejor resolución para evaluar distribuciones espaciales, aspectos ecológicos y procesos tafonómicos en escalas amplias. En razón de esto, la aproximación de este trabajo se vincula específicamente a la dimensión espacial del problema, no obstante lo cual se especifican las dataciones disponibles para el área y se comentan los resultados de excavaciones de sondeo estratigráfico, como una forma de contar con referentes temporales.

\section{ÁREA DE ESTUDIO}

\section{Localización y características} medioambientales

El río Ibáñez está ubicado en las estribaciones orientales de los Andes ( 4560'S y 72 50 'O), en la XI Región de Aisén (Fig. 1) y es el único de los grandes ríos en Chile que corre de oeste a este. Con su nacimiento en las faldas del volcán Hudson (macizo separado del Campo de Hielo Norte), el río drena al lago General Carrera/Buenos Aires, que a 


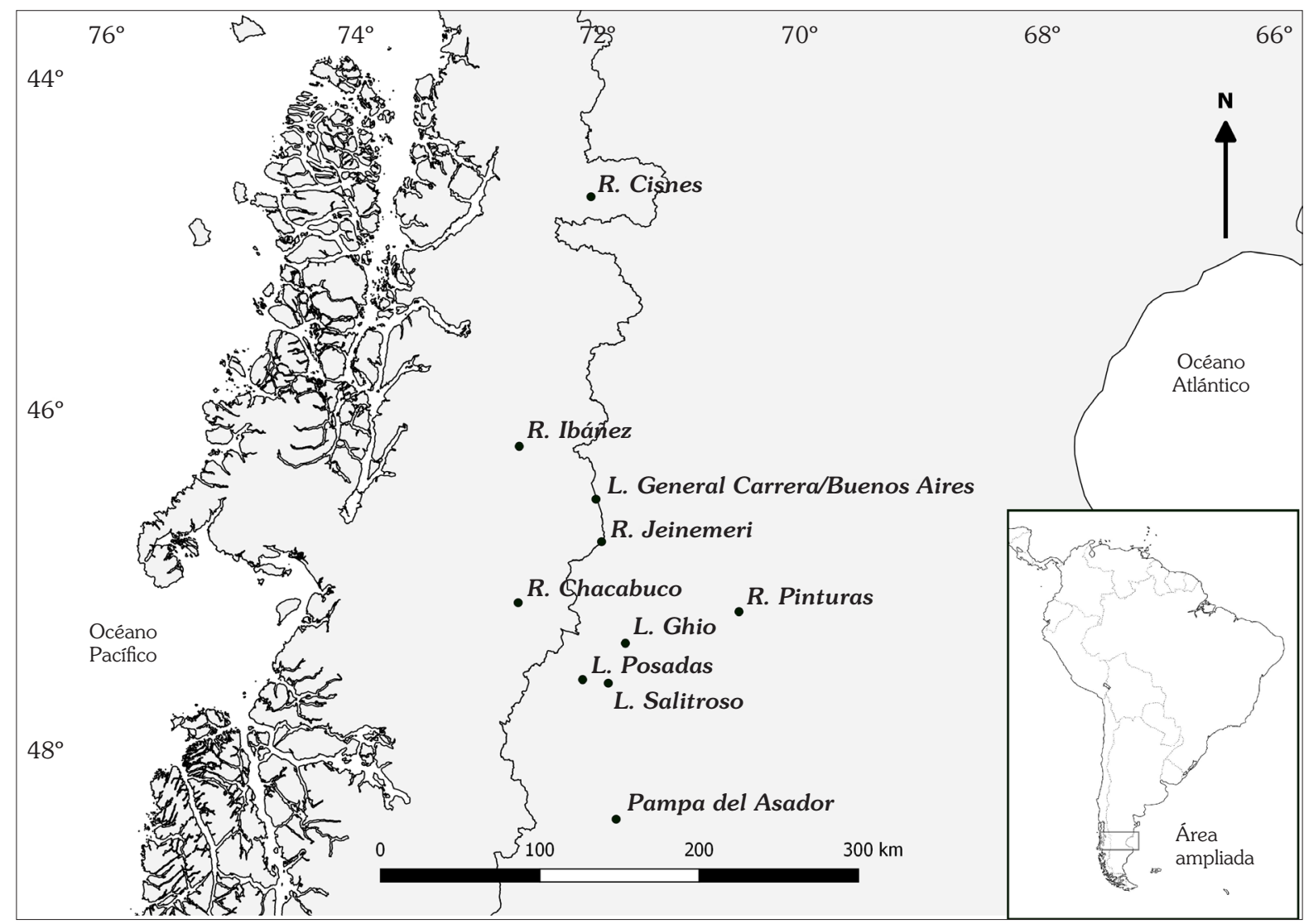

Fig. 1. Localización del río Ibáñez y de otros lugares mencionados en el texto.

su vez desagua al Pacífico a través del río Baker. De este modo, define un valle que corta una abrupta gradiente biogeográfica que se extiende por más de 85 kilómetros de largo, desde los bosques siempreverdes con abundantes precipitaciones anuales por el oeste, hasta los planos esteparios semiáridos en su desembocadura hacia el este. Más que un ecotono o una zona de transición gradual, se trata de un verdadero mosaico que responde a las variables de temperatura y precipitaciones, que varían desde el piso de la cuenca a unos 350 msnm hasta las altas cumbres nevadas que se empinan por sobre los $2000 \mathrm{~m}$ en la Reserva Nacional Cerro Castillo.

En el curso medio del río, el valle del Ibáñez está naturalmente limitado por el cauce del río y la cordillera Castillo al norte, los ríos Las Horquetas y Manso hacia el oeste y el lago Lapparent por el sur (Fig. 2). Hacia el oriente en cambio, tras la confluencia del Ibáñez con el río Claro (7156'O), el valle se abre hacia los planos esteparios que caracterizan el curso bajo y la desembocadura en el lago General Carrera/Buenos Aires. De esta forma, el valle medio del Ibáñez de unos $250 \mathrm{~km}^{2}$ de superficie, se presenta como un callejón sin salida hacia el oeste, marcado por un relieve escalonado que alberga una serie de cuencas con lagos, lagunas y cauces conectores. Está incluido en la ecorregión templada húmeda de verano fresco y mésico (CfsK) y la ecorregión boreal húmeda (Dfkc), con veranos cortos y secos e inviernos muy fríos (SERPLAC, 2005). Las precipitaciones disminuyen siguiendo un eje oeste-este, debido al efecto de sombra de lluvia de Los Andes que retienen la mayor parte de la humedad traída por el cinturón de vientos del oeste. En este ambiente se desarrolla el bosque caducifolio templado andino, dominado por lenga (Nothofagus pumilo) y coigüe ( $N$. betuloides), con arbustos como Berberis sp., Escallonia alpina y Maytenus disticha en las partes más bajas y secas, mientras que sobre el límite altitudinal del bosque (ca. 800-1000 msnm) se extiende el herbazal 


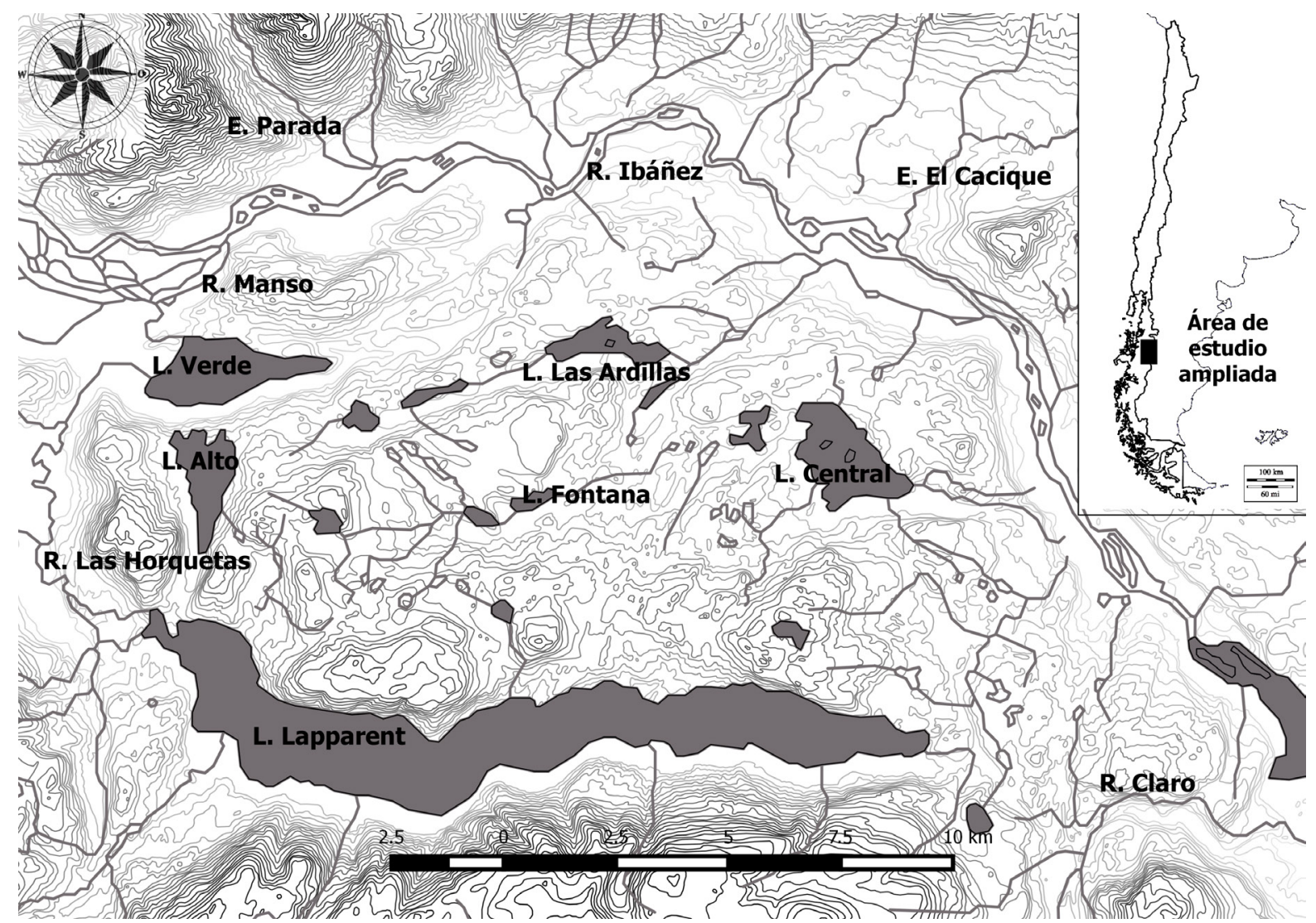

Fig. 2. Localización del área de estudio.

templado andino dominado por Nassauvia dentata, Senecio portalesianus, S. triodon y Berberis emperifolia. Al oriente de la confluencia con el río Claro, el bosque con presencia de ñire (Nothofagus antárctica) y lenga en terrenos altos, comienza a ceder paso a una vegetación de estepa arbustiva y herbácea con especies como Berberis microphylla y Ribes magellanicum (Luebert \& Pliscoff, 2006).

Geológicamente en el valle del curso medio del Ibáñez la expresión de los Andes patagónicos corresponde a la Formación Ibáñez, de origen volcánico, compuesta por tobas riolíticas y andesíticas, asociadas a rocas del Complejo Metamórfico del lago General Carrera. Con una topografía abrupta, presenta desniveles de cientos de metros en los que se pueden encontrar estrechos planos depositacionales intermontanos, asociados a los principales cursos fluviales (Quiroz \& Bruce, 2010). Los eventos eruptivos del volcán Hudson (4554'S), han depositado una importante cantidad de cenizas y materiales piroclásticos en el valle del Ibáñez durante el Holoceno medio y tardío (Stern, 1991; Naranjo \& Stern, 2004). En tiempos recientes el volcán Hudson ha tenido una serie de erupciones explosivas, siendo la de 1991 una de las mayores del siglo XX en todo el mundo, estimándose que habría expelido unos $4 \mathrm{~km}^{3}$ de piroclastos (Mena \& Buratovic, 1997).

Arqueología del valle del

curso medio del Ibáñez

Justamente en la sección media de la cuenca del Ibáñez es donde se localiza la mayor concentración de sitios arqueológicos, correspondientes mayoritariamente a aleros rocosos con pinturas rupestres, descritos a partir de la década de 1970 (Bate, 1970, 1971). Investigaciones sistemáticas iniciadas una década después registraron los yacimientos conocidos, realizaron excavaciones y sondeos estratigráficos, 
análisis de la distribución espacial del registro arqueológico y generaron un marco cronológico (Mena, 1983, 1987, 1989, 1990, 1991, 1992, 1999; Mena \& Ocampo, 1993).

Fruto de estas investigaciones fue el relevamiento de más de 60 sitios arqueológicos localizados en el curso medio e inferior del Ibáñez, principalmente entre los 300 y 650 msnm, protegidos del viento y con un ángulo visual amplio (Mena, 1991). Muchos de estos sitios son reparos rocosos con arte rupestre, mayoritariamente negativos de mano de color rojo y en menor medida motivos zoomorfos, grecas y placas (Lucero \& Mena, 2000). Excavaciones en sitios como RI16 , en el curso inferior del río, señalaron que las más tempranas ocupaciones correspondientes a cazadores estivales de guanacos se habrían producido alrededor de 5.300 años AP (Mena, 1983). Al interior del bosque caducifolio en el curso medio del río, excavaciones en el alero RI22, informaron de ocupaciones posiblemente invernales, asociadas a restos óseos de huemul (Hippocamelus bisulcus), raspadores y lascas en contextos ca. de 4.800 años AP (Mena, 1992; Velásquez \& Trejo, 2005). Otros lugares bajo alero en el curso medio muestran señales cronológicas más tardías hacia los 2.200 años AP (RI-55 y RI-22) y más tarde, entre 700 a 300 años AP asociadas a puntas pedunculadas con aletas. Recientes excavaciones en RI-6 Este y RI-23, ambos reparos rocosos con numerosos negativos de manos pintados en sus paredes, han reportado fechas para las ocupaciones al interior del bosque en el Ibáñez medio entre 5.800 y 5.200 años A.P. (Tabla 1).

Con fechas del Holoceno tardío se registraron algunos contextos de entierros humanos en chenques, principalmente localizados en el curso inferior del Ibáñez y en menor medida en el curso medio, con dataciones de ca. de 650 años AP en el sitio RI-45 (Reyes, 2002). Es interesante notar que los enterramientos bajo acumulaciones de piedra se encuentran más numerosamente representados en la desembocadura del río Ibáñez (por ejemplo en RI-89 con 14 chenques datados entre 600 y 300 años AP) y en sectores orientales estepáricos como la costa sur del lago General Carrera (Ericksen, 1965-1966), el lago Salitroso, Posadas, Pueyrredón y Ghío (Reyes, 2001, 2002;
Goñi et al. 2004).

Otro tipo de evidencia identificada en el valle del curso medio del Ibáñez son concentraciones de artefactos líticos en superficie, caracterizadas por una alta proporción de desechos e instrumentos expeditivos versus una escasa proporción de formatizados. Entre estos últimos predominan los instrumentos para raspar y raer, principalmente en el área más cercana a la ribera sur del río, así como el instrumental de corte y aserrado hacia el sur. Entre las materias primas se observó una alta incidencia de rocas silíceas por sobre la obsidiana, el basalto y la andesita (Mena \& Ocampo, 1993). Estudios geoquímicos de muestras de obsidiana procedentes de RI-50 señalaron su relación al tipo PDA I procedente de pampa del Asador en la provincia de Santa Cruz en Argentina (Stern et al. 1995), lo que ha sido confirmado para otros sitios en el último tiempo (Stern et al. 2013).

La distribución de las evidencias arqueológicas en el valle del curso medio del Ibáñez muestra dos agrupamientos, uno hacia norte, entre la ribera sur del río y el lago Las Ardillas y otro por el sur, entre el lago Central y la confluencia con el río Claro (Fig. 3). Ambos espacios podrían representar zonas de campamentos residenciales con cierta estabilidad, mientras que un sector intermedio en torno a los lagos Central y Las Ardillas, presentaría ocupaciones más efímeras y oportunistas (Mena \& Ocampo, 1993).

Análisis posteriores de artefactos líticos de superficie (Peralta, 2005), identificaron en sitios del valle medio una alta diversidad de materias primas de buena calidad para la talla (Aragón \& Franco, 1997), transportadas desde localidades cercanas como la cuenca inferior del Ibáñez (sílices) y del río Jeinemeni (sílices y dacita), así como desde lugares distantes como el lago Posadas (andesita) y de Pampa del Asador (obsidiana). Las rocas locales de regular calidad de talla, como el basalto, la andesita y otras rocas de grano grueso están representadas mayoritariamente en instrumentos de molienda, piqueteados-pulidos y de filos vivos, así como por escasos desechos, derivados de núcleo y raspadores, principalmente entre las cuencas del lago Central y de la laguna Las Ardillas. En la ribera sur del río Ibáñez y en el área de confluencia con el Claro se observó la utilización de rocas transportadas de buena calidad para la 
Tabla 1. Dataciones disponibles para el área de estudio.

\begin{tabular}{clcccl}
\hline Sitio & Material & Código & 14 C años AP & Años Cal AP & \multicolumn{1}{c}{ Referencias } \\
\hline RI-23 & Carbón & UGAMS 13214 & $5.850 \pm 30$ & $6.743-6.566$ & Mena, 2016 \\
RI-23 & Carbón & UGAMS 13217 & $5.820 \pm 25$ & $6.719-6.543$ & Mena, 2016 \\
RI-6 Este & Óseo animal & UGAMS 10802 & $5.270 \pm 30$ & $6.180-5.939$ & Mena, 2016 \\
RI-22 & Óseo animal & Beta-27304 & $4.830 \pm 60$ & $5.709-5.330$ & Mena \& Ocampo, 1993 \\
RI-23 & Carbón & UGAMS 13215 & $2.370 \pm 25$ & $2.465-2.341$ & Mena, 2016 \\
RI-55 & Carbón & GIF 7993 & $2.290 \pm 90$ & $2.699-2.058$ & Mena \& Ocampo, 1993 \\
RI-22 & Carbón & Beta-26401 & $2.110 \pm 60$ & $2.307-1.935$ & Mena \& Ocampo, 1993 \\
RI-57 & Óseo animal & UGAMS 21782 & $1.970 \pm 20$ & $1.986-1.876$ & Esta publicación \\
RI-6 Este & Carbón & UGAMS 10803 & $1.860 \pm 25$ & $1.868-1.724$ & Mena, 2016 \\
RI-6 Este & Óseo animal & UGAMS 11757 & $1.740 \pm 25$ & $1.710-1.570$ & Mena, 2016 \\
RI-64 & Carbón & UGAMS 13213 & $1.520 \pm 25$ & $1.521-1.345$ & Mena, 2016 \\
RI-6 Este & Carbón & UGAMS 10804 & $1.410 \pm 20$ & $1.345-1.291$ & Mena, 2016 \\
RI-22 & Carbón & Beta-26399 & $690 \pm 100$ & $892-514$ & Mena \& Ocampo, 1993 \\
RI-45 & Óseo humano & UGAMS 9223 & $640 \pm 25$ & $666-556$ & Mena, 2016 \\
RI-81 & Carbón & UGAMS 10801 & $590 \pm 20$ & $646-541$ & García \& Mena, 2016 \\
RI-22 & Carbón & Beta-47685 & $500 \pm 110$ & $668-314$ & Mena \& Ocampo, 1993 \\
RI-22 & Carbón & Beta-47684 & $460 \pm 90$ & $646-309$ & Mena \& Ocampo, 1993 \\
RI-18 & Óseo humano & CAMS-71701 & $410 \pm 40$ & $538-308$ & Reyes, 2002 \\
RI-5 & Carbón & Beta-82544 & $410 \pm 70$ & $538-308$ & Mena \& Buratovic, 1997 \\
RI-55 & Carbón & Beta-26402 & $400 \pm 40$ & $519-317$ & Mena \& Ocampo, 1993 \\
RI-6 Oeste & Carbón & UGAMS 10800 & $380 \pm 30$ & $505-319$ & Mena, 2016 \\
RI-23 & Carbón & UGAMS 13216 & $360 \pm 25$ & $498-317$ & Mena, 2016 \\
RI-22 & Carbón & Beta-26398 & $340 \pm 50$ & $497-306$ & Mena \& Ocampo, 1993 \\
RI-6 Oeste & Madera & UGAMS 10805 & $180 \pm 20$ & & Mena, 2016 \\
\hline & & & & \\
\hline
\end{tabular}

talla, como sílices y obsidiana, con las cuales se fabricaron instrumentos formatizados. En el caso de la obsidiana, dada su menor disponibilidad, alta calidad y mayor distancia a la fuente, su circulación en el curso medio del Ibáñez habría operado bajo una conducta de conservación, denotada en el mayor grado de formatización de los instrumentos. Sin embargo, se observó un procesamiento diferencial de esta materia prima en el valle: en el sector sur se fabricaron instrumentos $y$ se aprovecharon también los derivados de núcleos como filos vivos, mientras que en la ribera sur del río, se elaboraron, reavivaron y descartaron artefactos bifaciales (Peralta, 2005). Este procesamiento diferencial de la obsidiana podría relacionarse a diferencias en su abastecimiento a lo largo de un probable circuito de transporte de aproximadamente 250 kilómetros entre Pampa del Asador y la desembocadura del río Ibáñez (Méndez, 2004).

La comparación del registro arqueológico del curso medio del río Ibáñez, con su curso inferior, así como otros valles orientales de la región de Aisén y de áreas vecinas en la provincia de Santa Cruz, permitió identificar ciertas particularidades de las ocupaciones de cazadores recolectores en el Ibáñez. En primer término, de acuerdo a las dataciones radiocarbónicas disponibles (Tabla 1), la ocupación humana del valle sería más tardía que 


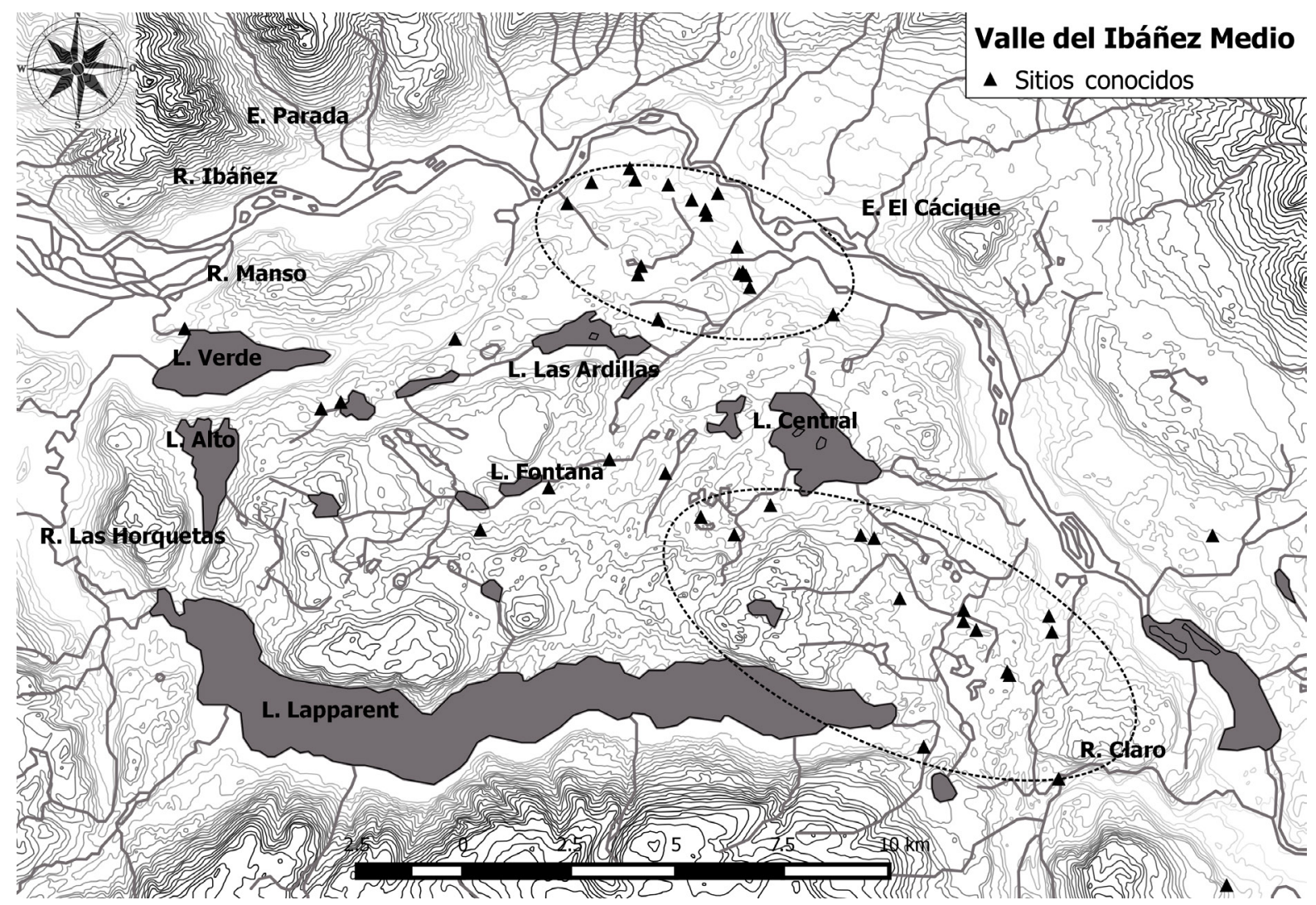

Fig. 3. Sitios arqueológicos conocidos en el Valle del Ibáñez Medio y espacios de agrupamiento.

la observada en áreas al oriente, observándose tres pulsos radiocarbónicos: uno, entre 5.800 y 4.800 años AP (definido por cuatro dataciones); otro, entre 2.300 y 1.400 años AP. (con ocho dataciones); y el último entre 700 y 200 años AP (con 11 dataciones). Entre estos pulsos se advierten dos lapsos temporales presumiblemente sin señal arqueológica: uno entre 4.800 y 2.300 años $\mathrm{AP}$ y otro entre 1.400 y 700 años AP. Estos hiatos en la cronología, podrían deberse al sesgo inherente del tamaño y composición de la muestra, aunque también podrían relacionarse a los avances neoglaciales registrados en varios puntos de la región de Aisén en los últimos 4.500 años (Markgraf et al. 2007; Mardonez et al. 2011) y/o a los eventos eruptivos del volcán Hudson (Naranjo \& Stern, 1998), los cuales podrían haber modificado, de manera profunda pero temporalmente restringida, las condiciones de habitabilidad del valle del Ibáñez.

Un segundo aspecto que se ha destacado es la abundancia de pinturas rupestres, particularmente de manos rojas en negativo y positivo, en la mitad este del valle. Esta situación contrasta con lo observado en áreas vecinas como el curso inferior del Ibáñez, los valles de Jeinemeni y Chacabuco hacia el sur (Mena, 1999; Mena \& Lucero, 2004; Quemada, 2008), donde también existe una alta oferta de reparos rocosos, pero en estos no siempre se pinta o se pintan otros motivos.

Un tercer aspecto se relaciona con la explotación de recursos específicos del valle del Ibáñez. Se trataría principalmente de madera para la confección de artefactos y el aprovechamiento de la alta disponibilidad de fuentes de agua permanentes, en las que pueden encontrarse además, animales, aves y peces. Hasta ahora el registro arqueofaunístico ha señalado una mayor proporción de restos óseos de huemul en las excavaciones de los aleros RI-22, RI-23 y RI-6 (Mena, 1992; Mena et al. 2004; Velásquez \& Trejo, 2005). La caza de este animal y de otras potenciales presas menores, como el pudú o el zorro, presentan desafíos peculiares a los cazadores en el bosque, debido a su baja predicibilidad y agrupamiento. 
Estos desafíos podrían ser superados con el manejo de una base de información locacional (sensu Rockman, 2003), que permitierá identificar y acceder existosamente a rutas de tránsito o lugares específicos de ocupación durante el ciclo anual, donde se seguiría una estrategía de caza por encuentro haciendo uso de armas arrojadizas, como se ha planteado para otras áreas de bosques en la Patagonia (Fernández \& Carballido, 2015).

Un último aspecto relacionado a la tecnología lítica y a las materias primas utilizadas, señala la participación del valle del Ibáñez en amplios circuitos de movilidad y transporte de materias primas alóctonas, que se extenderían entre el curso inferior del río y Pampa del Asador. Con estas materias primas se habrían fabricado instrumentos formatizados a través de talla bifacial, como puntas de proyectil pedunculadas, raederas y raspadores. Las rocas locales de menor calidad de talla, se utilizan de manera más oportunista ante su alta disponibilidad para elaborar instrumental de molienda y en menor medida raspadores, con ausencia de bifacialidad (Peralta, 2005). Nuevos estudios del paisaje lítico del valle indican la presencia de potenciales fuentes de materias primas en la ribera norte del río Ibáñez, entre el lago Las Ardillas y el lago Central, así como en la vertiente norte del lago Lapparent. Las materias primas identificadas son mayoritariamente de regular a mala calidad de talla, como la andesita, el basalto y la toba, mientras que algunas de buena calidad, como variedades de calcedonia o jaspe, se encuentran disponibles como inclusiones pequeñas en otras rocas o en lugares muy acotados (Gómez, 2013).

La constatación de las particularidades del registro arqueológicos del valle medio del Ibáñez, abrieron la discusión sobre el uso de ambientes específicos, la existencia de diferencias culturales a nivel de localidades y finalmente, la posibilidad de explorar microidentidades y restricción territorial (Mena, 1999, 2013). En el marco de un reciente proyecto de investigación, se planteó la necesidad de investigar más sistemáticamente las ideas de restricción territorial y la existencia de sistemas culturales cerrados. Uno de los supuestos que ello implica es que habría una concentración más o menos discreta de evidencias arqueológicas rodeadas por zonas de borde más o menos impermeables. Para evaluar esta hipótesis se implementó un programa de prospecciones en las áreas limítrofes de la distribución arqueológica conocida en el valle del curso medio del río Ibáñez, donde no se había realizado esta tarea en investigaciones anteriores. Consecuentemente, la prospección cuyos resultados exponemos en este trabajo, tuvo por objetivo evaluar la propuesta de limite del sistema cultural, investigando justamente aquellas zonas del valle donde no se contaba con registros arqueológicos.

\section{METODOLOGÍA}

\section{Sectorización del área de estudio}

Específicamente el área de estudio corresponde al valle del curso medio del río Ibáñez, el cual abarca una superficie cercana a los $250 \mathrm{~km}^{2}$. En dicho territorio se prospectaron con anterioridad aproximadamente $100 \mathrm{~km}^{2}$ en la mitad este del valle donde se reportaron numerosos hallazgos arqueológicos (Mena \& Ocampo, 1993). Por esta razón se definió operacionalmente un área de estudio acotada a la mitad oeste del valle, entre el piedemonte del cordón Castillo por el norte; las riberas orientales de los ríos Manso y Las Horquetas hacia el oeste; la costa del lago Lapparent hacia el sur y, una línea que sigue el meridiano $72^{\circ} 03^{\prime} 01.11^{\prime \prime} O$ señala el limite por el este. Para prospectar este territorio, se realizó una división del mismo en tres sectores, los cuales rodean por el norte, oeste y sur el área de mayor concentración de hallazgos conocidos (Fig. 4).

Los criterios utilizados para dividir el área de estudio en sectores fueron básicamente geográficos y sobre todo operacionales. Estos últimos responden a las actuales condiciones de accesibilidad vial, a la división de la propiedad de la tierra, a la densa cobertura de bosques y a lo abrupto y accidentado del relieve, factores que afectan sensiblemente las estrategias de prospección pedestre y que ya hemos descrito con detalle en otro trabajo (García \& Mena, 2016). Los tres sectores definidos comprenden una superficie total de $192 \mathrm{~km}^{2}$ y se caracterizan de la siguiente forma:

a) Sector Norte: comprende una superficie de $35 \mathrm{~km}^{2}$ entre la ribera septentrional del río 


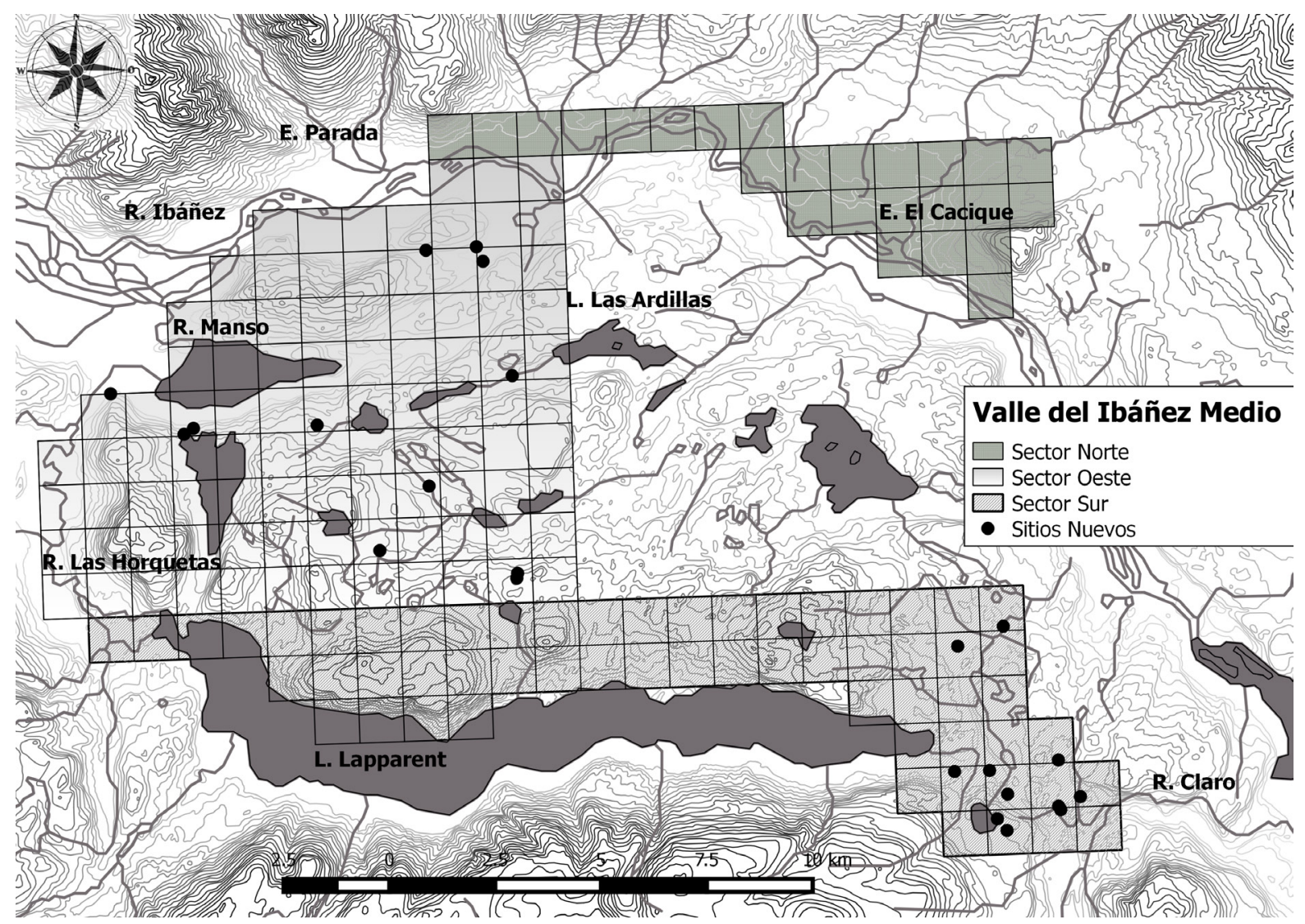

Fig. 4. Sectores de prospección y hallazgos arqueológicos en el área de estudio.

Ibáñez y el piedemonte de la cordillera Castillo por el norte (aproximadamente hasta la cota de $600 \mathrm{msnm})$, el estero Parada hacia el oeste y el estero El Cacique al este (Fig. 4). En las partes bajas presenta condiciones ecológicas dominadas por una disminución de las temperaturas y las precipitaciones que definen una vegetación con parches de bosque denso dominado por lenga entre praderas y arbustos bajos. El sector ocupa la primera terraza fluvial, la cual se extiende como una estrecha franja en sentido oeste-sureste entre el río y las montañas, donde se distinguen diferentes condiciones para la prospección. El área más cerca del curso actual del río, en cotas entre 300 y 350 msnm, presenta anchos planos de depositación fluvioaluvial y zonas anegadizas pantanosas con matorral bajo y disperso. Las áreas sobre el curso actual del río, por encima de la cota de $350 \mathrm{msnm}$, presentan pendientes suaves a moderadas y en ellas los tipos forestales de lenga y siempreverde presentan amplia dispersión con claros de praderas creados por el hombre para faenas agrícolas y ganaderas. Finalmente, un área por sobre los 400 msnm, con pendiente fuerte y altos murallones rocosos que corresponden al piedemonte de cimas que se alzan por sobre los $1000 \mathrm{msnm}$. En esta área se encuentran estrechos y profundos valles cortados entre las montañas andinas con esteros de gran caudal y una densa cobertura de bosque.

Este sector presenta mejor accesibilidad, tránsitoyvisibilidadquelosotrossectores, aún cuando una variedad de condiciones microtopográficas afectan la prospección (barrancos profundos, altos acantilados, cauces correntosos por ejemplo). Además, por su cercanía a la localidad de Villa Cerro Castillo, existe mayor división de la tierra y una utilización más específica de los terrenos (por ejemplo, aeródromo, cementerio), lo cual resulta en amplias áreas disturbadas por la actividad humana, donde los fuertes vientos ayudan a erosionar los suelos. 
b) Sector Oeste: definido entre la ribera del Ibáñez por el norte, los ríos Las Horquetas y Manso hacia el oeste, el paralelo $46^{\circ} 12$ 'S por el sur y una línea que sigue el meridiano $76^{\circ} 12^{\prime} \mathrm{O}$ entre el extremo occidental del lago Las Ardillas y oriental de la laguna Fontana como límite este (Fig. 4). Abarca un accidentado territorio de aproximadamente $92 \mathrm{~km}^{2}$, caracterizado por cuencas secundarias altas rodeadas de cumbres moderadas en todas direcciones. Inmediatamente al sur del río Ibáñez se encuentran relieves montanos que se empina hasta los 500 msnm y algunos que superan los $1000 \mathrm{msnm}$ alrededor de los lagos Verde y Alto. El sector comprende también parte de las cuencas tributarias de los ríos Las Horquetas y Manso, así como numerosas cuencas lacustres grandes y pequeñas tales como Fontana, Las Ardillas, Alto y Verde.

En términos ecológicos, esta área se caracteriza por la baja general de las temperaturas y un incremento de las amplitudes térmicas, así como por altas precipitaciones y mayor humedad relativa, las que disminuyen gradualmente hacia el este. En este marco, la vegetación dominante es el bosque caducifolio templado andino, principalmente compuesto por lenga y coigüe, así como por especies siempreverdes en laderas umbrías. Donde el bosque ha sido disturbado por actividades humanas, los vientos del oeste deflacionan los sectores bajos, contribuyendo a la generación de cárcavas y desplazamientos por gravedad en sectores altos. Las cenizas de la erupción del Hudson de 1991 se encuentran ampliamente distribuidas en este sector empobreciendo la visibilidad de superficies sin vegetación.

c) Sector sur: comprende una superficie de $65 \mathrm{~km}^{2}$, entre el lago Lapparent por el sur y una línea que sigue los $46^{\circ} 12^{\prime} \mathrm{S}$ al norte, el río Las Horquetas hacia el oeste y el río Claro al este (Fig. 4). El lago Lapparent está bordeado por sistemas montañosos que tienen término en el espejo de agua. Las laderas se elevan por sobre los $1000 \mathrm{msnm}$, con pendientes siempre fuertes y densamente vegetadas. El hecho que buena parte de estas laderas sean umbrías y por consiguiente húmedas, permite dar cobijo a una abundante vegetación de matorral y árboles siempreverdes, lenga y ñires
(Nothofagus antarctica). Por esta razón resulta un área difícil para el tránsito humano y en ella los depósitos de cenizas de la erupción del volcán Hudson de 1991 contribuyen a la mala visibilidad de la superficie. El acceso a este espacio es en la actualidad, tanto desde el oeste como desde el este extremadamente difícil, a pesar de la existencia de caminos. Por ejemplo, las cumbres que rodean el lago Lapparent, presentan superficies amesetadas que, o permanecen cubiertas de nieve todo el año o pueden recibirla durante buena parte éste; estas cimas caen en fuerte pendiente al Lapparent, lo que hace inexistente una franja de costa o playa. En los márgenes oeste y este del lago se encuentran terrenos bajos, aunque extremadamente boscosos, por los cuales es factible transitar pero difícilmente observar la superficie del suelo, debido a la vegetación, la hojarasca, el material leñoso y las cenizas volcánicas depositadas sobre él.

\section{Unidades de prospección y \\ estrategia de muestreo}

Para definir las unidades de prospección, los tres sectores del área de estudio fueron divididos en cuadrantes de un $\mathrm{km}^{2}$. Esto permitió dimensionar la superficie prospectable de manera pedestre y estimar la intensidad y cobertura posibles de alcanzar con tiempos y recursos restringidos. Para dimensionar la superficie prospectable se hizo uso de cartografía, herramientas de SIG e imágenes satelitales, con las cuales se identificaron las superficies por donde no es posible caminar, como los numerosos cuerpos lacustres y cursos fluviales. Una vez definida la superficie que podía ser prospectada en cada sector, se seleccionó un diseño de muestreo aleatorio simple de los cuadrantes de cada sector, que permitiera cubrir al menos un $20 \%$ de la superficie total prospectable.

Las prospecciones se llevaron a cabo en cuatro temporadas entre 2012 y 2014 , ajustándose a diferentes tiempos, cantidad y preparación del personal. El sector oeste fue prospectado por 10 personas durante 14 días; en el sector norte, se utilizaron tres días y cuatro personas, mientras que en el sector sur, trabajaron siete personas durante siete días. Estas variaciones, se expresan en los diferentes valores de cobertura para cada sector, es decir la proporción de superficie efectivamente 
Tabla 2. Superficie y cobertura de los sectores del área de estudio.

\begin{tabular}{ccccc}
\hline Sector & $\begin{array}{c}\text { Superficie total } \\
\left(\mathrm{km}^{2}\right)\end{array}$ & $\begin{array}{c}\text { Superficie } \\
\text { prospectable }\left(\mathrm{km}^{2}\right)\end{array}$ & $\begin{array}{c}\text { Superficie } \\
\text { prospectada }\left(\mathrm{km}^{2}\right)\end{array}$ & $\begin{array}{c}\text { Cobertura por } \\
\text { sector }(\%)\end{array}$ \\
\hline Oeste & 92 & 76,5 & 23 & 30,1 \\
Norte & 35 & 27,2 & 8,9 & 32,7 \\
Sur & 65 & 56 & 6,2 & 11,1 \\
Total & 192 & 159,7 & 38,1 & 23,9 \\
\hline
\end{tabular}

prospectada (Tabla 2).

En cada temporada de trabajo, uno o más equipos compuestos por dos a tres arqueólogos, tenían la tarea de prospectar uno o dos cuadrantes cada día, monitoreando la cobertura efectiva mediante el registro del recorrido con dispositivos GPS. De esta manera, la superficie cubierta fue calculada considerando la longitud del trayecto de un prospector $y$ un ancho de cuatro metros (sobre la base de que la visión de la superficie a más de dos metros a cada lado de un observador no es factible). Los datos de longitud y posición de cada trayecto fueron descargados de los dispositivos de GPS a mapas digitales, con los cuales se estimó la superficie cubierta en cada cuadrante.

La forma de los recorridos de los observadores en terreno fue planificada como transectas con una separación de $50 \mathrm{~m}$ entre los miembro del equipo. Sin embargo, los desplazamientos de los observadores en pocos lugares concordaron con una trayectoria de línea recta, como sucedió en espacios con pendientes suaves o abiertos por las actividades humanas. En los sectores oeste y sur, donde el bosque es denso y el relieve abrupto, los desplazamientos tuvieron que ajustar su distancia entre sí al punto de visibilidad entre los miembros del equipo y los desplazamientos siguieron generalmente cursos en líneas onduladas paralelas. $\mathrm{Si}$ bien se ha descrito que semejante trayectoria tiene la ventaja de que estrecha la distancia entre los prospectores y les permite observar la superficie desde diferentes direcciones, rebajando la probabilidad de omitir hallazgos (Banning, 2002), la forma final del recorrido de cada miembro del equipo fue más bien impuesta por el terreno que seleccionada de un marco metodológico.

Además de la georeferenciación de los hallazgos y de los recorridos de prospección, los equipos debían recoger la totalidad de los materiales identificados y registrar información sobre la vegetación dominante, el grado de pendiente, la distancia a fuentes de agua permanentes, exposición al viento, visibilidad y visibilización, agentes de alteración y otros datos de interés contextual.

Con vistas a complementar la información de superficie, se seleccionaron algunos lugares detectados en la prospección o conocidos de antemano en los diferentes sectores, para realizar excavaciones de sondeos estratigráficos. Estos loci fueron elegidos de acuerdo a su condición (abierto o bajo alero), la cantidad y/o diversidad de materiales superficiales, las características de los suelos, por sus dimensiones, condiciones de refugio o la presencia de manchas de color rojo en las paredes que pudiesen corresponder a pinturas antiguas mal conservadas. De esta forma, se seleccionaron en el sector oeste cinco aleros rocosos y dos loci a cielo abierto con materiales en superficie. En el sector sur se realizaron excavaciones solo en el alero con pinturas RI-11 (Bate, 1970), aunque fuera del programa de prospección y sondeo del cual damos cuenta aquí, razón por la cual solo se hará una somera mención a sus resultados. Finalmente, consignamos que en el sector norte no se realizaron excavaciones de sondeos estratigráficos, debido a los pobres resultados obtenidos en la prospección.

\section{RESULTADOS}

La visibilidad restringida de la superficie es una característica común a los tres sectores de prospección, principalmente debido a la cubierta herbácea, arbustiva y de bosques caducifolios, así como por los depósitos de cenizas y piroclastos de la erupción del volcán Hudson de 1991. Debido a estas restricciones los prospectores aprovecharon ventanas de visibilidad disponibles en sectores erosionados por el viento, abiertos por intervenciones antrópicas recientes (caminos, huellas y senderos, sectores desforestados) y en los numerosos 
aleros y paredones rocosos existentes en todos los sectores. La identificación de hallazgos aislados y concentraciones fue siempre hecha en sectores erosionados por el viento o por acción humana reciente, mientras que la alta visibilidad de los aleros rocosos permitió que se hallaran sitos con pinturas $\mathrm{u}$ otras evidencias en terrenos boscosos.

El acceso a los cuadrantes seleccionados aleatoriamente para prospectar, fue una tarea consumidora de tiempo y energías debido a las largas distancias entre la red de caminos existentes y la mayor parte de los cuadrantes. Además, el acceso se vio dificultado por la presencia de nieve, esteros crecidos, zonas anegadas, la pendiente, el bosque o accidentes topográficos. Estos elementos, que ciertamente influyeron en el tránsito de los prospectores, fueron determinantes de los trayectos individuales y afectaron la cobertura de prospección en cada sector.

La cobertura total de la prospección alcanzó el 23,9\%, superando ligeramente nuestra expectativa del $20 \%$ de la superficie prospectable (Tabla 2). Sin embargo, la cobertura en cada sector fue diferente. En el sector sur, la accesibilidad y la pendiente fueron determinantes en la baja proporción de superficie cubierta. En el sector oeste, de mayor superficie prospectable, se alcanzó un $30 \%$ de cobertura, en virtud de la mayor cantidad de tiempo y personal implicado en la prospección. Mientras que en el sector norte, de menor superficie, se alcanzó el 32\% de cobertura, a pesar de emplear menor cantidad de tiempo y personal.

Se registraron 23 nuevos contextos arqueológicos, distribuidos en baja densidad en los sectores oeste y sur (Tabla 3). En el sector norte, no se registro ningún tipo de evidencia, con la excepción de la confirmación de una concentración de artefactos líticos ya conocida y denominada RI59 (Mena \& Ocampo, 1993), la cual no había podido ser localizada tras la caída de cenizas del volcán Hudson en 1991 Los nuevos hallazgos están comprendidos en cuatro tipos: hallazgos aislados, concentraciones de artefactos, aleros con pinturas y un cuarto tipo, denominado como

1 Posteriores análisis de fotografías digitales llevadas a cabo con el programa ImageJ y su complemento DStretch, permitieron descartar la presencia de motivos pintados en aleros con otra evidencia, el cual corresponde a aleros con algún tipo de material en superficie, pero originalmente registrados por tener posibles pinturas antiguas muy desvaídas en sus paredes ${ }^{1}$.

Tabla 3. Frecuencia y densidad de nuevos hallazgos en cada sector según tipo.

\begin{tabular}{lcc} 
& Sector Oeste & Sector sur \\
\hline Superficie prospectada $\left(\mathrm{Km}^{2}\right)$ & 23 & 6,2 \\
Hallazgos aislados & $4(33,3 \%)$ & $5(45,5 \%)$ \\
Concentraciones & $4(33,3 \%)$ & $3(27,3 \%)$ \\
Aleros con pinturas & $2(16,7 \%)$ & $3(27,3 \%)$ \\
Aleros con otra evidencia & $2(16,7 \%)$ & 0 \\
Total de hallazgos & $12(100 \%)$ & $11(100 \%)$ \\
Densidad general de hallazgos & 0,5 & 1,8 \\
\hline
\end{tabular}

\section{Sector Oeste}

Se registraron 12 nuevos loci, entre los que se recolectaron 53 artefactos líticos. De acuerdo a la superficie prospectada en este sector $\left(23 \mathrm{~km}^{2}\right)$, la densidad alcanza a 0,5 artefactos $/ \mathrm{km}^{2}$. Los hallazgos aislados y concentraciones de artefactos líticos a cielo abierto son ligeramente más frecuentes (Tabla 3), aún cuando se identificaron materiales líticos aislados o como pequeña concentración bajo alero.

La localización de los nuevos hallazgos a través del perfil altitudinal, muestra que la mayoría de los loci a cielo abierto se localizan en cotas bajas (entre 300 y 500 msnm). En ellas los hallazgos se localizaron en claros erosivos al interior del bosque caducifolio o en paisajes de vegetación arbustiva más abierta, donde la visibilidad hacia los lugares de hallazgos es de media a alta. Tanto los hallazgos aislados como las concentraciones se encuentran en terrenos de pendientes moderadas a fuertes $y$ solo en un caso de pendiente baja. Por otro lado, los hallazgos de aleros rocosos se produjeron entre los 350 y más de 800 msnm, aunque mayoritariamente fueron localizados sobre los 600 msnm. En un caso, un paredón con arte rupestre fue registrado por sobre los $800 \mathrm{msnm}$, siendo el más alto loci con pinturas conocido hasta ahora en el valle.

dos aleros, identificando un graffiti moderno y manchas correspondientes a la oxidación natural de la roca andesítica que forma los aleros. 
Tabla 4. Frecuencia y diversidad de artefactos líticos y materias primas en el sector oeste.

\begin{tabular}{cccccccccc}
\hline \multicolumn{2}{c}{ Materias primas } & \multicolumn{7}{c}{ Tipo de artefactos } \\
\hline \multirow{2}{*}{ Fuente } & Tipo & Núcleo & $\begin{array}{c}\text { Desechos } \\
\text { de talla }\end{array}$ & $\begin{array}{c}\text { Lascas } \\
\text { retocadas }\end{array}$ & Cuchillo & Raspador & Raedera & Cepillo & Total \\
\hline \multirow{4}{*}{ Local } & Andesita & 0 & 0 & 0 & 0 & 1 & 0 & 1 & 2 \\
& Basalto & 1 & 19 & 0 & 0 & 0 & 0 & 2 & 22 \\
& Cuarcita & 0 & 0 & 1 & 0 & 0 & 0 & 0 & 1 \\
\hline \multirow{2}{*}{ Foránea } & Calcedonia & 0 & 1 & 1 & 0 & 0 & 0 & 0 & 2 \\
& Sílices & 0 & 3 & 4 & 0 & 0 & 0 & 0 & 7 \\
& Obsidiana & 0 & 12 & 4 & 1 & 1 & 1 & 0 & 19 \\
\hline \multicolumn{2}{c}{ Total general } & 1 & 35 & 10 & 1 & 2 & 1 & 3 & 53 \\
\hline
\end{tabular}

Entre los artefactos líticos recolectados en la prospección, la mayor parte corresponde a desechos de talla y en menor medida a lascas retocadas $e$ instrumentos relacionados con actividades de mantención, tales como cepillos, raspadores, cuchillos y raederas (Tabla 4 ).

Las materias primas foráneas de buena calidad para la talla, están ligeramente más representadas que las variedades de rocas locales entre los artefactos recuperados. La mayor parte de las lascas retocadas y de los instrumentos están confeccionados en obsidiana, calcedonia y sílices, así como buena parte de los desechos de talla. No se observaron núcleos y la incidencia de corteza en estas materias primas es escasa, señalando un posible transporte en forma de matrices o instrumentos, desde los lugares de abastecimiento. En el caso de la obsidiana los desechos de talla se relacionan al retoque o reactivación de filos y es la única materia prima en la que se observa bifacialidad entre los instrumentos.

Las rocas locales como el basalto, la andesita, riolita y cuarcita, se encuentran en menor proporción entre los materiales recolectados en este sector (44,3\%). Los desechos de talla de basalto son el tipo más común, relacionándose a etapas de desbaste de núcleos y el adelgazamiento inicial de matrices. El único núcleo registrado en este sector es de basalto y proviene de la concentración RI-77, donde se registraron un total de 41 piezas líticas. De esta concentración provienen también dos cepillos toscos confeccionados sobre núcleos de basalto, un raspador sobre una lasca rota de sílice $y$ un fragmento de bifaz de obsidiana retomado como raedera.
En un alero rocoso (RI-74), al pie de un gran paredón visible en un claro de bosque, se identificaron cuatro áreas pintadas, con una sola mano en negativo visible en color rojo. La excavación de un pozo de sondeo de 0,25 $\mathrm{m}^{2}$ en su interior, no identificó materiales ni rasgos arqueológicos. En un sector alto, también en medio del bosque de lenga se reconoció en un paredón rocoso de escaso alero una negativo de mano izquierda de color rojo, muy desvaído aunque visible. Si bien en este paredón (RI-84) no efectuaron excavaciones de sondeo, representa el sitio más alto conocido hasta ahora con motivos pintados en el valle del Ibáñez.

Otros tres aleros fueron seleccionados para sondeos, en virtud de su superficie y de la presencia de posibles pinturas. En un caso, identificado como alero Calfullanca 2 (AC2), se excavaron cuatro pozos de sondeo de $0,25 \mathrm{~m}^{2}$ en su interior $y$ paralelos a la línea de goteo, donde se registraron restos óseos de animales domésticos (Ovis sp.) en los niveles superficiales y un pequeño rasgo de combustión a $30 \mathrm{~cm}$ de profundidad. En el alero RI81 , se excavaron cinco pozos de $0,25 \mathrm{~m}^{2}$ al interior y paralelos a la línea de goteo, registrándose restos óseos posiblemente de huemul, un desecho de talla lítica de calcedonia con retoques marginales y un rasgo de combustión a $50 \mathrm{~cm}$ de profundidad del cual se obtuvo un datación de ca. 600 años AP (García \& Mena, 2016). Por último, en RI76 se excavaron tres pozos de sondeo donde se registraron desechos de talla lítica en silice, obsidiana y basalto, un retocador óseo y algunas astillas óseas hasta los $60 \mathrm{~cm}$ de profundidad (García \& Mena, 2016).

Dos aleros rocosos conocidos por los 
lugareños y visitados anteriormente, fueron seleccionados para la excavación de sondeos. En el alero RI-40 se excavaron dos sondeos de $0,5 \mathrm{~m}^{2}$ junto a la pared de fondo, que presenta un negativo de mano rojo y una macha del mismo tono. En estos sondeos se recuperaron escasos materiales líticos presentes entre 50 y $70 \mathrm{~cm}$ de profundidad. Estos corresponden a desechos de talla principalmente de rocas no locales (obsidiana, sílice y calcedonia), un fragmento de raspador frontal y un sobador/ percutor de basalto, un raspador simple sobre una lámina de obsidiana y un fragmento de núcleo silíceo. Junto con estos materiales se recolectaron restos óseos aún no determinados y espículas de carbón.

El segundo caso corresponde al alero RI-64, el cual presenta en sus paredes algunas manchas rojas que podrían corresponder a pinturas borrosas, así como un positivo de mano de color negro muy desvaído. En su interior se excavó un pozo de sondeo de $0,25 \mathrm{~m}^{2}$, en el cual solo se registraron trozos de carbón de los cuales se obtuvo una datación para la base a $80 \mathrm{~cm}$ de profundidad de aproximadamente 1.500 años AP.

Entre los hallazgos a cielo abierto, se seleccionaron dos concentraciones líticas para sondeos estratigráficos. La primera denominada RI77 , se localizó muy cerca de una laguna estacional y a poca distancia de los aleros RI-76 y AC2. En este lugar se excavaron dos sondeos de 0,25 $\mathrm{m}^{2}$ cada uno, sobre la superficie deflacionada por el viento donde se registraron los materiales líticos y otro sobre el terreno inmediato no erosionado, pero en ninguna de estas pruebas se encontraron materiales culturales.

Otra pequeña concentración de artefactos líticos denominada RI-78, fue localizada en el extremo noroeste del lago Alto, en medio de un camino vehicular. Los materiales corresponden principalmente a lascas de obsidiana con presencia de corteza y en menor medida de sílice y basalto, un cuchillo sobre lámina de obsidiana y un cepillo de dorso alto sobre un núcleo de andesita. En este lugar también se excavó un pozo de 0,25 $\mathrm{m}^{2}$ donde se encontraron los materiales y otro de igual tamaño sobre una superficie fuera del camino, ambos sin resultados.

El sector oeste incluye seis lugares que fueron descubiertos previamente (Bate, 1970;
Mena \& Ocampo, 1993). Se trata de seis aleros con numerosas pinturas (RI-22, RI-27, RI-28, RI30, RI-40 y RI-64), en su mayoría negativos de manos de color rojo, aunque también se observan positivos (algunos posiblemente de niños), grecas y conjuntos geométricos. Entre estos destaca el alero Fontana (RI-22) tanto por sus pinturas como por la información aportada por su excavación, relacionada a ocupaciones de cazadores recolectores, probablemente en invierno, con una importante explotación de animales del bosque, principalmente huemul, zorro (Lycalopex sp.) y pudú (Pudu pudu). Para estas ocupaciones existen dataciones entre 4.800 y 2.100 años AP para el Componente Temprano y 700 a 300 años AP para el Componente Tardío (Mena, 1992; Velásquez \& Trejo, 2005).

\section{Sector Sur}

En el sector sur se identificaron 11 nuevos contextos arqueológicos, entre los que se recolectaron 53 artefactos. De acuerdo a la superficie prospectada del sector $\left(6,2 \mathrm{~km}^{2}\right)$, la densidad de artefactos es de 1,8 artefacto/ $\mathrm{km}^{2}$, superior a la del sector oeste en virtud de la menor superficie prospectada. La mayor parte de los nuevos hallazgos fueron hechos en lugares abiertos y corresponden a materiales aislados y concentraciones de artefactos líticos. Bajo alero se identificaron tres loci con pinturas, principalmente negativos de manos en color rojo.

Los nuevos hallazgos a cielo abierto de este sector se concentran principalmente entre los 500 y los $600 \mathrm{msnm}$, en claros al interior del bosque caducifolio o en zonas erosionadas en paisajes de vegetación arbustiva o herbácea, donde la visibilidad de los puntos de hallazgos es alta. Se registró una pequeña concentración de materiales líticos a 793 msnm, siendo el hallazgo a cielo abierto más alto registrado en toda la prospección. En todos los casos los materiales fueron hallados en terrenos de pendiente baja a moderada. En el caso de los aleros, estos se localizaron entre 550 y $770 \mathrm{msnm}$, principalmente en medio del bosque caducifolio y en solo un caso en un área de vegetación herbácea y bosque abierto, donde la visibilidad a los aleros es de media a alta.

La mayor parte de los artefactos líticos 
Tabla 5. Frecuencia y diversidad de artefactos líticos y materias primas en el sector sur.

\begin{tabular}{|c|c|c|c|c|c|c|c|c|c|c|}
\hline \multicolumn{5}{|c|}{ Materias primas } & \multicolumn{6}{|c|}{ Tipos de artefactos } \\
\hline Fuente & Tipo & Núcleo & $\begin{array}{c}\text { Desechos } \\
\text { de talla }\end{array}$ & $\begin{array}{l}\text { Lascas } \\
\text { retocadas }\end{array}$ & Bifaz & Raspador & Raedera & Cuchillo & Cepillo & Total \\
\hline \multirow{6}{*}{ Local } & Andesita & 1 & 0 & 1 & 0 & 0 & 0 & 0 & 1 & 3 \\
\hline & Basalto & 0 & 7 & 2 & 0 & 0 & 0 & 0 & 0 & 9 \\
\hline & Cuarzo & 0 & 1 & 0 & 0 & 0 & 0 & 0 & 0 & 1 \\
\hline & Riolita & 0 & 3 & 1 & 0 & 1 & 0 & 0 & 0 & 5 \\
\hline & Toba & 0 & 1 & 0 & 0 & 0 & 0 & 0 & 0 & 1 \\
\hline & $\begin{array}{l}\text { No } \\
\text { determinado }\end{array}$ & 0 & 2 & 0 & 0 & 0 & 0 & 0 & 0 & 2 \\
\hline \multirow{3}{*}{ Foránea } & Calcedonia & 0 & 2 & 0 & 0 & 1 & 0 & 1 & 0 & 4 \\
\hline & Obsidiana & 0 & 19 & 1 & 0 & 1 & 0 & 0 & 0 & 21 \\
\hline & Sillices & 0 & 4 & 0 & 2 & 0 & 1 & 0 & 0 & 7 \\
\hline \multicolumn{2}{|c|}{ Total general } & 1 & 39 & 5 & 2 & 3 & 1 & 1 & 1 & 53 \\
\hline
\end{tabular}

recolectados en estos contextos corresponden a desechos de talla y en menor medida a lascas retocadas. Se hallaron también tres raspadores, una raedera, un cuchillo, un cepillo, un bifaz fracturado y un núcleo de andesita. Con valores muy semejantes a lo observado en el sector oeste, las materias primas más representadas son la obsidiana, sílices y calcedonia (Tabla 5). Solo entre estas materias primas se observa el uso de talla bifacial, específicamente en sílice, que aparece representado con dos fragmentos de un mismo bifaz, pero que no remontan. Los desechos de talla de obsidiana por ejemplo, se relacionan al retoque y reavivado de instrumentos y en menor medida al adelgazamiento de matrices, donde la presencia de corteza es mínima, sugiriendo el desbaste de núcleos en otro lugar y el transporte de matrices.

Las rocas locales, al igual que en el sector oeste, están menos representadas entre los artefactos líticos recolectados. Entre ellos los desechos de talla de basalto son el tipo más común $y$ estos se relacionan principalmente al desbaste de núcleos. De riolita se identificaron desechos de talla, una lasca con retoque marginal y un raspador. En andesita se registra un fragmento de núcleo con remanentes de corteza, así como un cepillo sobre una lasca nodular con corteza y una lasca con retoques marginales (Tabla 5).

De manera similar a lo observado en el sector oeste, los materiales líticos del sector sur fueron principalmente registrados en una concentración (RI-96), emplazada al noreste del lago Lapparent entre parches de bosque y vegetación arbustiva. Allí se recolectaron 44 piezas líticas dispersas en el borde de un camino vehicular, entre las que hay un cuchillo, una raedera, raspadores laterales y frontales, un cepillo de dorso medio y una alta frecuencia de obsidiana en desechos de talla. Además, en este loci se identificó un fragmento de cerámica correspondiente a la unión cuello - cuerpo de una vasija restringida, con tratamiento alisado interior, pulido exterior, de posible factura indígena. Este tipo de hallazgos son escasos entre los contextos de cazadores de la Patagonia centro meridional, si bien se han registrado fragmentos en algunos sitios del sector de Cisnes alto, Pallavicini y Entrada Baker en Aisén (Mena \& Jackson, 1991; Mena \& Lucero, 2004; Valásquez et al. 2007) y Magallanes (Martinic \& Prieto, 1998) en Chile, así como en la vecina Provincia de Santa Cruz en Argentina (Cassiodoro et al. 2014). Esta tecnología provendría de territorios más septentrionales y en general, se asocia a una cronología tardía, datada por termoluminiscencia para el curso bajo del río Ibáñez en $405 \pm 40$ años AP (Mena \& Lucero, 2004) y en $740 \pm 80$ años AP para el alto río Cisnes (Velásquez et al. 2007).

Al sureste del lago Lapparent se registró el alero rocoso RI-97, en un sector de pendientes 
suaves y de transición esteparia con parches de bosque abierto. El bloque que conforma el reparo presenta al menos cinco negativos de manos muy desvaídos en el techo y numerosas manchas de color rojo en las paredes. A poco más de $1500 \mathrm{~m}$ al este, se registró otro loci con pinturas (RI-98), al interior de un bosque de lenga. Se trata de una alta pared vertical, que en algunos sectores ofrece algo de alero y donde se observaron al menos 11 negativos y un positivo de mano principalmente de color rojo, además de numerosas manchas también rojas sin formas definidas. Otro hallazgo cercano de pinturas en el bosque se realizó en una ladera de fuerte pendiente que enfrenta una laguna, donde se localizó una pequeña cueva o gruta que denominamos RI-99 y en cuyas paredes se distinguieron algunas manchas rojas y un posible motivo de mano en la pared de fondo parcialmente cubierto con líquenes.

Otros tres aleros rocosos con pinturas fueron identificados con anterioridad a nuestro trabajo en este sector. Uno de estos, denominado RI-11, presenta numerosos negativos de manos rojas y blancas, así como desechos de talla y un fragmento de hueso con pintura roja, obtenidos en un pozo de sondeo (Bate 1970). Análisis preliminares de nuevos sondeos efectuados en este alero, han registrado consumo de huemul y un conjunto lítico numeroso, compuesto principalmente por desechos de reavivado y retocado de instrumentos, así como de adelgazamiento de matrices, raspadores y raederas en obsidiana, sílices y calcedonias. De manera semejante a lo observado en conjuntos de superficie, las rocas locales son menos frecuentes entre los desechos de talla, la mayoría de los cuales se vinculan al desbaste de núcleos; los instrumentos son escasos (solo un raspador frontal) al igual que los núcleos. Los nuevos sondeos estratigráficos han obtenido fechas de aproximadamente 4.500 años AP para el componente inferior y de ca. 1.800 años AP para el componente superior.

Otro alero rocoso con pinturas es RI-24, localizado cerca de la ribera oriental del lago Lapparent (Bate, 1971). En este lugar se han identificado al menos cuatro figuras de camélidos superpuestos, así como cuatro negativos de manos en rojo, uno de las cuales podría ser de un niño. Más al oriente, sobre el río Claro se encuentra el alero RI-65, con numerosos negativos de manos y una posible mano de moler en el talud exterior (Sade, 2008). Con anterioridad se identificaron dos concentraciones de artefactos líticos al noreste del Lapparent en paisajes de transición esteparia, denominadas RI-49 y RI-50, donde hay registro de raspadores, cuchillos, raederas, principalmente en rocas foráneas (sílices, obsidiana, chert, calcedonia) y también de una bola y un tajador en materias primas locales (granito, basalto) (Mena \& Ocampo, 1993). El análisis geoquímico de una muestra de obsidiana de RI-50 permitió su asignación al tipo PDA I de Pampa del Asador (Stern et al. 1995; Méndez, 2001).

Cercano a estas concentraciones se encuentra el alero RI-55, con una datación de ca. de 2.200 años AP para un contexto somero en la base de la excavación, así como otra de ca. de 400 años AP para una contexto donde destaca una punta pedunculada con aletas, cuchillos, raederas, un molino y desechos de talla principalmente de obsidiana, sílices y chert (Mena \& Ocampo, 1993).

\section{DISCUSIÓN Y CONCLUSIONES}

Los resultados obtenidos en la prospección del valle del curso medio del río Ibáñez, han mostrado la presencia de contextos arqueológicos en las áreas limítrofes, principalmente hacia el oeste. Si bien la frecuencia de hallazgos arqueológicos y la densidad de artefactos son bajas en los sectores prospectados, estarían de acuerdo con la idea de un área limítrofe donde la densidad de artefactos y/o contextos es menor a la observada en las áreas de concentración de sitios, entre la ribera sur del Ibáñez y la laguna Las Ardillas, hacia el norte y entre el lago Central y el río Claro por el sur.

Los hallazgos realizados en la prospección muestran similares características a las observadas en los contextos conocidos: uso de aleros, pinturas de manos en negativo preferentemente rojas, artefactos líticos para tareas de mantención (como raspadores, raederas y cepillos) y uso preferente de materias primas de buena calidad para la talla transportadas desde fuera del valle. De acuerdo a los análisis de los materiales líticos recolectados en las prospecciones, se puede plantear que existe cierta 
concordancia en relación a la cantidad y tipos de materiales registrados tanto en superficie como a través de los sondeos. Esto podría apuntar a que la baja densidad y diversidad artefactual podría no ser un sesgo de visibilidad de la superficie o cobertura de la prospección, sino una característica de las zonas limítrofes.

Los nuevos hallazgos extienden de manera efectiva el límite de la distribución espacial hasta la ribera de los ríos Las Horquetas y el Manso por el oeste, siendo factible plantearlos como una barrera (aunque permeable) para la dispersión. Sin duda, este planteamiento necesita de más trabajo al oeste de estos ríos para conocer la efectividad de la barrera. Una situación diferente se daría en el sector sur, donde los nuevos hallazgos se concentran en un territorio entre el río Claro y la ribera oriental del lago Lapparent, el cual se encuentra relativamente cerca (en un radio menor a tres kilómetros) de numerosos sitios conocidos en este sector del valle y también de aquellos que pertenecen a la cuenca baja del Ibáñez. Por esta razón, los hallazgos del sector sur, parecen no representar una zona limítrofe, sino más bien ser parte de la dispersión arqueológica que es relativamente continúa hacia el suroriente.

No se registraron nuevos contextos arqueológicos en el sector norte y hasta ahora, más allá de la ribera septentrional del río Ibáñez solo se conoce una concentración de artefactos líticos en superficie (Mena \& Ocampo, 1993). De acuerdo a la ausencia de nuevos hallazgos y a la baja frecuencia de contextos conocidos, cabe plantear la posibilidad de que el río Ibáñez haya conformado una barrera o límite hacia el norte para los cazadores recolectores que ocuparon el valle durante el Holoceno tardío. Sin embargo, esta situación solo podría obedecer a las diferencias de muestreo en ambas riberas del Ibáñez y su contrastación requiere de mayor trabajo a futuro en el sector norte.

Por otro lado, las materias primas líticas de buena calidad para la talla y en general de origen foráneo, observadas en los sectores oeste y sur, siempre presentan frecuencias superiores a las rocas locales, de menor calidad de talla. Entre las materias primas provenientes de fuera del valle del Ibáñez, la obsidiana es la de mayor representación con lascas y láminas de pequeño tamaño y espesor, así como escasa presencia de corteza. Análisis de muestras de obsidiana han identificado la variedad PDA I en el valle del Ibáñez medio (Stern et al. 1995, 2014), lo que hace posible plantear -como ya fue señalado antes en el curso inferior del Ibáñez (Méndez, 2004)- que el sistema cultural observado en el valle medio del Ibáñez, presenta una apertura hacia el oriente y estaría participando de un sistema mayor de movilidad y circulación de materias primas que se extiende a la estepa oriental.

Otro elemento a considerar, es la distribución de las manifestaciones pictóricas en reparos rocosos. Los nuevos hallazgos realizados en la prospección (más allá de la complejidad observada por su estado conservación o ambigüedad de formas), consisten principalmente de manos en negativo y menos en positivo, de color rojo. Estos motivos aparecen profusamente distribuidos en la zona central del valle (Lucero \& Mena, 2000) y, de acuerdo a esto los nuevos hallazgos corresponderían a una extensión espacial del fenómeno, aunque en menor frecuencia. Es importante notar, sin embargo, que esta extensión espacial contempla dos detalles que amplían su conocimiento. El primero se relaciona a la localización de un negativo de mano por sobre los $800 \mathrm{msnm}$, superando la distribución conocida de sitios con pinturas a menos de $700 \mathrm{msnm}$. El segundo detalle es que no se registraron pinturas en sectores como la ribera oeste del lago Lapparent o la oriental del río Las Horquetas, donde la disponibilidad natural de aleros es más alta que en otros sectores del valle. Lamentablemente, a la fecha no contamos con dataciones directas de pinturas que nos permitan verlas desde una perspectiva temporal a lo largo del valle del Ibáñez.

Los resultados de las prospecciones ofrecen dos elementos importantes para discutir la hipótesis sobre el funcionamiento de un sistema cultural territorialmente restringido en el valle del Ibáñez. Por un lado, sobre los posibles límites, se advierte que al norte del río Ibáñez, la señal arqueológica es muy débil. Que por el oeste, la densidad de hallazgos y artefactos es baja, existiendo además similitudes formales con las pinturas rupestres registradas en la mitad este del valle. Mientras que hacia el sur, los hallazgos 
se concentran hacia el extremo sudeste de la superficie prospectada, muy cerca del área donde se ha registrado la mayor parte de los sitios arqueológicos del valle (Mena \& Ocampo, 1993) y del curso inferior del Ibáñez, como para intentar separarlos. En consecuencia, parece plausible que hacia el oeste y norte los cursos fluviales hayan funcionado como límites naturales, mientras que al sur, el macizo que se levanta sobre la ribera norte del lago Lapparent, podría haber actuado de manera similar. En consecuencia, los límites naturales del valle del Ibáñez, podrían haber funcionado como barreras para la circulación humana y habrian restringido espacialmente a los grupos de cazadores recolectores durante su ocupación en el Holoceno tardío. Estas barreras, sin duda debieron ser permeables para los grupos humanos y no deben ser entendidas como absolutas. El hecho de que no conozcamos en la actualidad dónde y cómo podrían haber sido superadas, no nos habilita a definirlas como barreras impermeables a la movilidad humana, al mismo tiempo que nos obliga a investigar la situación del otro lado de estos límites naturales.

Con relación al grado de cierre o apertura de este sistema, un elemento importante para considerar es la presencia de obsidiana entre los artefactos líticos. Como se ha señalado antes, en sitios del valle del Ibáñez fue identificada una variedad proveniente de Pampa del Asador (Stern et al. 1995, 2014), por lo cual nos parece probable que los artefactos de obsidiana recolectados durante las nuevas prospecciones, puedan tener el mismo origen. Si este fuera el hecho, podríamos plantear que el sistema cultural del Ibáñez medio, tiene una apertura hacia el este, dirigida entre otras cosas, al aprovisionamiento de obsidiana (ya sea a través de acceso directo o de intercambio). Al mismo tiempo, si se considera la presencia de arte rupestre a lo largo del Ibáñez, su total ausencia o mínima presencia en valles vecinos de Aisén y su posible relación con expresiones de territorios al este (como el valle del río Pinturas, o los territorios en torno a los lagos Pueyrredón, Posadas y Salitroso), la factibilidad de la participación del sistema cultural del Ibáñez en un sistema más amplio y con base en la estepa oriental parece aumentar.

Los resultados aquí presentados y la discusión que hemos planteado, señalan sin duda la necesidad de ampliar el estudio arqueológico más allá de los límites naturales del valle del Ibáñez y explorar más atentamente las relaciones con los territorios al oriente, norte y sur. La necesidad de aumentar las dataciones y de contar específicamente con ellas para analizar el arte rupestre, son parte de los nuevos desafíos que la investigación deberá afrontar en el futuro.

\section{BIBLIOGRAFÍA}

Aragón, E., \& Franco, N. (1997). Características de rocas para la talla por percusión y propiedades petrográficas. Anales del Instituto de la Patagonia, 25, 187-199.

Banning, E. (2002). Archaeological survey. New York: Kluwer Academic/Plenum Publishers.

Bate, F. (1970). Primeras investigaciones sobre el arte rupestre de la Patagonia Chilena. Anales del Instituto de la Patagonia, 1(1), 15-25.

Bate, F. (1971). Primeras investigaciones sobre el arte rupestre de la Patagonia chilena (segundo informe). Anales del Instituto de la Patagonia, 2, 33-41.

Bordieu, P. (1988). La distinción. Criterios y bases sociales del gusto. Madrid: Taurus.

Borrero, L., Charlin, J., Barberena, R., Martin, F., Borrazo, K., \& L'Heureux, L. (2008). Circulación humana y modos de interacción al sur del río Santa Cruz. En L. Borrero, \& N. Franco (Eds.), Arqueología del extremo sur del continente sudamericano. Resultados de nuevos proyectos (pp. 155-174). Buenos Aires: Consejo Nacional de Investigaciones Científicas y Técnicas.

Borrero, L., Barberena, R., Franco, N., Charlin, J., \& Tykot, R. (2009). Isotopes and rocks: geographical organization of southern Patagonian hunter-gatherers. International Journal of Osteoarchaeology, 19, 309-327.

Casamiquela, R. (1969). Un nuevo panorama etnológico del area pan-pampeana y patagónica adyacente: pruebas etnohistóricas de la filiación tehuelche septentrional de los querandies. Santiago: Ediciones del Museo Nacional de Historia Natural.

Cassiodoro, G., Espinosa, S., Re, A. Belardi, J., Nuevo, A., Piriz, F., \& Durou, G. (2014). Tecnología de la cuenca del Lago Cardiel. En R. Goñi, J. Belardi, G. Cassiodoro, \& A. Re (Eds.), Arqueología de las cuencas de los lagos Cardiel y Strobel. Poblamiento humano y paleoambientes en Patagonia (pp. 67-95). Buenos Aires: Aspha Ediciones

Charlin, J., \& Borrero, L. (2012). Rock art, inherited landscapes, 
and human populations in Southern Patagonia. En J. McDonald, \& P. Veth (Eds.), A Companion to Rock Art (pp. 381-397). Sussex: Willey-Blackwell.

Ericksen, M. (1965-1966). Restos óseos provenientes de Chile Chico: (Provincia de Aisén, Chile). Revista Universitaria, (28-29), 351-366.

Escalada, F. (1949). El complejo" tehuelche”. Buenos Aires: Instituto Superior de Estudios Patagónicos.

Falkner, T. (2013). A description of Patagonia, and the adjoining parts of South America: containing an account of the soil, produce, animals, vales, mountains, rivers, lakes, etc. of those countries. Cambridge: Cambridge University Press.

Franco, N. (2008). La estructura tecnológica regional y la comprensión de la movilidad humana. En L. Borrero \& N. Franco (Eds.), Arqueología del extremo sur del continente americano. Resultados de nuevos proyectos (pp. 119-154). Buenos Aires: Consejo Nacional de Investigaciones Científicas y Técnicas.

Franco, N. (2013). ¿Es posible diferenciar la existencia de grupos humanos con áreas de circulación distintas en el extremo sur de Patagonia durante el Holoceno tardío? En F. Zangrando, R. Barberena, A. Gil, G. Neme, M. Giardina, L. Luna, C. Otaola, S. Paulides, L. Salgán, \& A. Tivoli (Eds.), Tendencias teórico-metodológicas y casos de estudio en la arqueología de la Patagonia (pp. 363-370). San Rafael: Museo de Historia Natural de San Rafael.

Fernández, P., \& Carballido, M. (2015). Armas y presas. Técnicas de caza en el interior del bosque patagónico. Relaciones de la Sociedad Argentina de Antropología, 40(1), 279-301.

García, C., \& Mena, F. (2016). ¿La frontera del oeste? Prospecciones arqueológicas en el bosque montano del extremo occidental del valle medio del río Ibáñez (Andes patagónicos, Chile). Intersecciones en Antropología, 17, 49-61.

Giddens, A. (1994). Modernidad e identidad del yo. Península: Barcelona.

Gómez, M. (2013). Aprovechamiento de recursos líticos en el valle del río Ibáñez (Patagonia central), una aproximación a partir de los conjuntos de superficie. Tesis para Título Profesional de Arqueóloga, Universidad de Chile, Santiago.

Goñi, R., Barrientos, G., Figuerero, M., Mengoni, G., Mena, F., Lucero, V., \& Reyes, O. (2004). Distribución espacial de entierros en la cordillera de la Patagonia centromeridional (lago Salitroso-Paso Roballos Arg / Entrada Baker-río Chacabuco). Chungará, Vol. Esp., 1101-
1107.

Lucero, V., \& Mena, F. (2000). Arte rupestre del río Ibáñez (XI región): un análisis cuantitativo exploratorio. En J. Belardi, F. Carballo \& S. Espinoza (Eds.), Desde el país de los gigantes. Perspectivas arqueológicas en Patagonia (pp. 415-427). Río Gallegos: Universidad Nacional de la Patagonia Austral.

Luebert, F., \& Pliscoff, P. (2006). Sinopsis bioclimática y vegetacional de Chile. Santiago: Universitaria.

Mardones, M., González, L., King, R., \& Campos, E. (2011). Variaciones glaciales durante el Holoceno en Patagonia central, Aisén, Chile: evidencias geomorfológicas. Andean Geology, 38(2), 371-392.

Markgraf, V., Whitlock, C., \& Haberle, S. (2007). Vegetation and fire history during the last 18,000 cal yr B.P. in Southern Patagonia: Mallín Pollux, Coyhaique, Province Aisén (4541'30” S, 7150'30” W, 640 m elevation). Palaeogeography, Palaeoclimatology, Palaeoecology, 254, 492-507.

Martinic, M., \& Prieto, A. (1998). La cerámica entre los aonikenk. Anales del Instituto de la Patagonia, 26, 77-82

Mena, F. (1983). Excavaciones arqueológicas en Cueva Las Guanacas (RI-16), XI Región. Anales del Instituto de la Patagonia, 14, 65-75.

Mena, F. (1987). Investigaciones sobre cazadores continentales en Aysén (Chile) Comunicaciones. Primeras Jornadas de Arqueología de la Patagonia (pp. 161-170). Trelew.

Mena, F. (1989). Hacia un panorama del registro arqueológico regional: promesas y frustraciones. Arqueología Contemporánea, 2(2), 31-52.

Mena, F. (1990). Prehistoric settlement patterns and resources distribution in the Middle Río Ibáñez, Central Patagonia. The Explorers Journal, 68(2), 84-87.

Mena, F. (1991). Prehistoric resources space and settlement at the Río Ibáñez valley (Central Patagonian Andes). Ph.D. dissertation, University of California, Los Angeles.

Mena, F. (1992). Mandíbulas y maxilares: un primer acercamiento a los conjuntos arqueofaunísticos del Alero Fontana (RI-22; XI Región). Boletín del Museo Nacional de Historia Natural, 43, 179-191.

Mena, F. (1999). La ocupación prehistórica de los valles andinos centro-patagónicos (XI Región, Chile): generalidades y localismos. En J. Belardi, P. Fernández, R. Goñi, A. Guráieb \& M. De Nigris (Eds.), Soplando en el viento. Actas de las III Jornadas de Arqueología de la Patagonia (pp. 57-64). Buenos Aires: Instituto Nacional 
de Antropología y Pensamiento Latinoamericano, Universidad Nacional del Comahue.

Mena, F. (2013). ¿Un caso de microidentidad y/o restricción territorial en el curso medio del río Ibáñez (Aisén, Andes centropatagónicos, Chile)? En F. Zangrando, R. Barberena, A. Gil, G. Neme, M. Giardina, L. Luna, C. Otaola, S. Paulides, L. Salgan \& A. Tivoli (Eds.), Tendencias teórico-metodológicas y casos de estudio en la arqueología de la Patagonia (pp. 187-192). San Rafael: Museo de Historia Natura de San Rafael.

Mena, F. (2016). Sistemas de movilidad restringida y circulación en el valle del río Ibáñez, Andes centropatagónicos, Chile. En F. Mena (Ed.), Arqueología de la Patagonia: de mar a mar (pp. 48-57). Santiago: Nire Negro Ediciones.

Mena F., \& Buratovic, C. (1997). Cenizas volcánicas y procesos de formación de sitios arqueológicos: un estudio actualístico preliminar en la Patagonia central chilena. Chungará 29(2):181-193.

Mena, F., \& Jackson, D. (1991). Tecnología y subsistencia en alero Entrada Baker región de Aisén, Chile. Anales del Instituto de la Patagonia, 20, 169-203.

Mena, F., \& Lucero, V. (2004). En torno a las últimas poblaciones indígenas de la cordillera centro-Patagónica: estudio comparado de tres valles en Aisén oriental (Chile). En M. Civalero, P. Fernández, \& A. Guráieb (Eds.), Contra viento y marea. Arqueología de Patagonia (pp. 643657). Buenos Aires: Instituto Nacional de Antropología y Pensamiento Latinoamericano.

Mena, F., \& Ocampo, C. (1993). Distribución, localización y caracterización de sitios arqueológicos en el río Ibáñez (XI Región). Boletín del Museo Regional de la Araucanía, 4(1), 33-58.

Mena, F., Velásquez, H., Trejo, V., \& Torre-Murúa, J. C. (2004). Aproximaciones zooarqueológicas al pasado de Aisén continental (Patagonia central chilena). En G. Mengoni Goñalons (Ed.), Zooarchaeology of South America (pp. 99-122). Oxford: BAR International Press 1298.

Méndez, C. (2001). Obsidiana negra en contextos arqueológicos de los valles andinos de Patagonia Central Chilena. Boletín de la Sociedad Chilena de Arqueología, 32, 35-42.

Méndez, C. (2004). Movilidad y manejo de recursos líticos de tres valles andinos de Patagonia centro oriental. En M. Civalero, P. Fernández, \& A. Guráieb (Eds.), Contra viento y marea. Arqueología de Patagonia (pp. 135147). Buenos Aires: Instituto Nacional de Antropología y Pensamiento Latinoamericano.

Naranjo, J., \& Stern, C. (1998). Holocene explosive activity of the Hudson volcano, Southern Andes. Bulletin of Vulcanology, 59, 291-306.

Naranjo, J., \& Stern, C. (2004). Holocene tephrochronology of the southernmost part $\left(42^{\circ} 30^{\prime}-45^{\circ} \mathrm{S}\right)$ of the Andean Southern Volcanic Zone. Revista Geológica de Chile, 31(2), 225-240.

Peralta, P. (2005). Integración de contextos del Ibáñez medio a las actuales problematicas de circulación y utilización de recursos líticos en Aisén (XI Región). En M. Massone (Ed.), Actas del XVI Congreso Nacional de Arqueología Chilena (pp. 583-592). Concepción: Ediciones Escaparate.

Quemada, C. (2008). Estudio comparativo del uso del espacio en cuatro valles en la región de Aisén oriental: valle del río Cisnes, valle del río Ibáñez, valle del río Jeinemeni, Valle del Río Chacabuco. (Tesis para optar al título de Arqueóloga), Universidad de Chile, Santiago.

Quiroz, D., \& Bruce, Z. (2010). Geología del área Puerto Ingeniero Ibáñez- Villa Cerro Castillo, Región de Aisén del General Carlos Ibáñez de Campo. Santiago: Servicio Nacional de Geología y Minería.

Reyes, O. (2001). Enterratorios indígenas en el curso inferior del valle del río Ibáñez, Región de Aisén. Boletín de la Sociedad Chilena de Arqueología, 31, 61-64.

Reyes, O. (2002). Funebria indígena en el curso inferior del valle del río Ibáñez, margen occidental de la estepa centropatagónica (XI región de Aisén). Anales del Instituto de la Patagonia, 30, 87-101.

Richerson, P., \& Boyd, R. (2006). Not by Genes Alone. Chicago: The University of Chicago Press.

Rockman, M. (2003). Knowledge and learning in the archaeology of colonization. En M. Rockman \& J. Steele (Eds.), Colonization of unfamiliar landscapes. The archaeology of adaptation (pp. 3-24). London: Routledge.

Sade, K. (2008). Cazadores extintos de Aysén continental: propuesta de poblamiento. Coyhaique: Nire Negro.

SERPLAC. (2005). Atlas región de Aysén. Santiago: LOM.

Stern, C. (1991). Mid-Holocene tephra on Tierra del Fuego $\left(54^{\circ} \mathrm{S}\right)$ derived from Hudson volcano $\left(46^{\circ} \mathrm{S}\right)$ : evidence for a large explosive eruption. Revista Geológica de Chile 18(2):110-126.

Stern, C., Castro, A., Pérez de Micou, C., Méndez, C., \& Mena, F. (2013). Circulación de obsidianas en Patagonia central-sur entre 44 y $46^{\circ}$ S. En F. Zangrando, R. Barberena, A. Gil, G. Neme, M. Guiardina, L. Luna, C. Otaola, S. Paulides, L. Salgán \& A. Tivoli (Eds.), Tendencias teórico-metodológicas y casos de estudio en la arqueología de la Patagonia 
(pp. 243-250). San Rafael: Museo de Historia Natura de San Rafael.

Stern, C., Mena, F., Aschero, C., \& Goñi, R. (1995). Obsidiana negra de los sitios arqueológicos en la precordillera andina de patagonia central. Anales del Instituto de la Patagonia, 23, 111-118.

Velásquez, H., \& Trejo, V. (2005). Alero Fontana: aprovechamiento específico del huemul. En M.
Massone (Ed.), Actas del XVI Congreso Nacional de Arqueología Chilena (pp. 557-566). Concepción: Escaparate.

Velásquez, H., Méndez, C., Reyes, O., Trejo, V., Sanhueza, L., Quiroz, D., \& Jackson, D. (2007). Campamentos residenciales tardíos a cielo abierto en el alto río Cisnes (región de Aisén): Apelleg 1 (Cis 009). Magallania, 35(1), 121-132. 
